\title{
The effect of baseline serum luteinizing hormone levels on follicular development, ovulation, conception and pregnancy outcome in infertile patients with polycystic ovarian syndrome
}

\author{
Deepa Shanmugham*, R. K. Vidhyalakshmi, Shivamurthy H. M.
}

Department of Obstetrics and Gynecology, Aarupadai Veedu Medical College, Pondicherry, India

Received: 26 October 2017

Accepted: 25 November 2017

*Correspondence:

Dr. Deepa Shanmugham,

E-mail: drdeepabalamurugan@gmail.com

Copyright: () the author(s), publisher and licensee Medip Academy. This is an open-access article distributed under the terms of the Creative Commons Attribution Non-Commercial License, which permits unrestricted non-commercial use, distribution, and reproduction in any medium, provided the original work is properly cited.

\begin{abstract}
Background: Polycystic Ovarian Syndrome (PCOS) is the most common endocrine disorder in infertile women. Raised tonic levels of luteinizing hormone $(\mathrm{LH})$ is one of the main endocrinological disturbances in PCOS patients. Objective of present study was to evaluate the effect of baseline serum luteinizing hormone levels on follicular development, ovulation and conception and pregnancy outcome in infertile patients with PCOS.

Methods: This is a prospective study conducted on 50 consecutive infertile patients with PCOS. Baseline Day 2 serum luteinizing hormone concentration was done in selected patients. Ovulation induction was done with clomiphene citrate $100 \mathrm{mg}$ from Day 3 to Day 7 of the cycle. Then patients were monitored for follicular development, ovulation, conception and early pregnancy loss.

Results: The mean age of the patients is $25 \pm 3.6$ yrs. The average duration of infertility is 5.4 yrs (2-10). The mean basal serum LH concentration in patients who ovulated was significantly low (5.6 IU) in comparison with patients who did not ovulate $(10.1 \mathrm{IU})$. The mean basal serum LH concentration in patients who conceived was 3.9 IU in comparison with patients who did not conceive $(5.9 \mathrm{IU})$ which was statistically significant $(\mathrm{p}=0.04)$. Out of 15 patients who conceived, 3 patients $(20 \%)$ had early pregnancy loss.

Conclusions: Tonic hyper secretion of LH results in premature oocyte maturation, causing the problems with fertilization and miscarriage. Inappropriately raised LH appears to have deleterious effects on the pregnancy outcome.
\end{abstract}

Keywords: Infertility, LH, Ovulation, PCOS

\section{INTRODUCTION}

Polycystic Ovarian Syndrome (PCOS) is the most common endocrine disorder in infertile women. Infertility affects $40 \%$ of women with PCOS. ${ }^{1}$ Polycystic ovary syndrome (PCOS), a relatively common reproductive endocrine disorder often associated with high endogenous LH secretion, menstrual cycle disorders, infertility and high rates of spontaneous abortion, was considered the paradigm condition that proved the potential untoward actions of LH.
Raised tonic levels of luteinizing hormone (LH) is one of the main endocrinological disturbances in PCOS patients. $^{2}$ This inappropriate secretion of $\mathrm{LH}$ seems to affect both fertility and pregnancy outcomes of PCOS women. Increased production of androgens associated with high LH concentrations, coupled with their inefficient aromatization to estrogens related to the low FSH levels in PCOS patients, results in local androgen excess and oestrogen deficit within the ovary. ${ }^{3}$ This would constitute a potent androgenic environment for the follicle leading to cessation of follicular growth. This 
forms the basis for the cause of infertility in patients with PCOS i.e., chronic anovulation.

Several investigators have reported that increased $\mathrm{LH}$ levels significantly reduced the fertilization and cleavage rates. $^{4,5}$ In spite of all these if pregnancy is established, higher rates of miscarriage are reported by few authors. ${ }^{6}$

However, few literatures are available on effect of high tonic levels of luteinizing hormone on folliculogenesis and ovulation. The aim of our study is to evaluate the effect of baseline serum luteinizing hormone levels on follicular development, ovulation and conception in infertile patients with Polycystic Ovarian Syndrome.

\section{METHODS}

This is a prospective study conducted in the department of obstetrics and gynaecology from July 2016 to June 2017 in a tertiary care centre after obtaining Institutional Ethics Committee clearance. 50 consecutive infertile patients with polycystic ovarian syndrome (PCOS) attending the infertility clinic were enrolled for the study. The exclusion criteria was tubal factor infertility, male factor infertility, endometriosis and women with other endocrine problems like hypothyroidism and hyperprolactinemia. A detailed history and gynaecological examination was done in all patients.

Baseline Day 2 serum luteinizing hormone concentration (World Health Organisation international reference preparation code number 68/40) was done in all selected patients. Basal Day 2 Transvaginal Ultrasound pelvis (Mindray Z 5) was done to measure the endometrial thickness and to rule out ovarian cyst if any.

Then, ovulation induction was done with clomiphene citrate $100 \mathrm{mg}$ from Day 3 to Day 7 of the cycle. Subsequent follicular monitoring was done by transvaginal sonogram from Day 9. Ovulation trigger with injection hCG 10,000 IU was done once the follicle reaches $18-20 \mathrm{~mm}$ size. Ovulation was detected by transvaginal sonogram by the visualisation of crumpled follicle and presence of free fluid in POD. Ovulated patients were advised to review after 15 days for the confirmation of pregnancy.

Pregnancy was confirmed by detection of HCG in urine and appearance of gestational sac in ultra sonogram. Patients who conceived were followed up for antenatal care. Statistical analysis was done with student $\mathrm{t}$ test.

\section{RESULTS}

50 patients were enrolled for the study and among them 2 patients lost follow up.

Table 1 shows the demographic characteristics of the 48 study patients. The mean age of the patients is $25 \pm 3.6$. The mean BMI of the patients is $27 \pm 2.2$. The average duration of infertility is 5.4 years (Range: 2-10 years). Out of 48 patients, 43 patients presented with primary infertility $(89 \%)$ whereas 5 patients $(11 \%)$ presented with secondary infertility. $75 \%$ of the patients presented with clinical features of hyperandrogenism like hirsuitism and acne.

Table 1: Demographic characteristics of study patients.

\begin{tabular}{ll} 
Parameter & Value/Percentage \\
\hline Mean Age & $25 \pm 3.6$ years \\
\hline Mean BMI & $27 \pm 2.2$ \\
\hline Duration of infertility & 5.4 years $(2-10$ years $)$ \\
\hline Primary infertility & 43 pts $(89 \%)$ \\
\hline Secondary infertility & 5 pts $(11 \%)$ \\
\hline Hyperandrogenism & $75 \%$ \\
\hline
\end{tabular}

Table 2 and 3 shows basal serum LH concentration in each group. Out of 48 patients, 27 patients (56\%) had good follicular development ovulated. Similarly, among 27 patients who ovulated and 15 patients $(55 \%)$ conceived.

Table 2: Comparison of mean base line serum LH concentration of patients based on ovulation.

\begin{tabular}{|llll} 
& $\begin{array}{l}\text { Group A } \\
\text { (Patients who } \\
\text { ovulated) } \\
\mathrm{n}=27\end{array}$ & $\begin{array}{l}\text { Group B } \\
\text { (Patients who } \\
\text { didn't ovulate) } \\
\mathrm{n}=21\end{array}$ & $\begin{array}{l}\text { P } \\
\text { value }\end{array}$ \\
\hline $\begin{array}{l}\text { Mean basal } \\
\text { serum LH }\end{array}$ & $5.6 \mathrm{IU} / \mathrm{L}$ & $10.1 \mathrm{IU} / \mathrm{L}$ & 0.0015 \\
\hline Range & $2.1-10.2 \mathrm{IU} / \mathrm{L}$ & $6.3-19 \mathrm{IU} / \mathrm{L}$ & \\
\hline
\end{tabular}

Table 3: Comparison of Mean base line serum LH concentration of patients based on conception.

\begin{tabular}{|llll} 
& $\begin{array}{l}\text { Group C } \\
\text { (Patients who } \\
\text { conceived) } \\
\mathrm{n}=15\end{array}$ & $\begin{array}{l}\text { Group D } \\
\text { (Patients who } \\
\text { didn't conceive) } \\
\mathrm{n}=12\end{array}$ & $\begin{array}{l}\mathrm{P} \\
\text { value }\end{array}$ \\
\hline $\begin{array}{l}\text { Mean basal } \\
\text { serum LH }\end{array}$ & $3.9 \mathrm{IU} / \mathrm{L}$ & $\mathbf{5 . 9} \mathrm{IU} / \mathrm{L}$ & 0.04 \\
\hline Range & $2.1-5.6 \mathrm{IU} / \mathrm{L}$ & $2.6-10.2 \mathrm{IU} / \mathrm{L}$ & \\
\hline
\end{tabular}

Statistical analysis was done with student $\mathrm{t}$ test (one tailed hypothesis) with significance level of 0.05. During the result analysis, patients were divided into those who ovulated (Group A) and who did not ovulate (Group B).

The basal serum LH concentration was compared in these 2 groups. The mean basal serum LH concentration in patients who ovulated $(n=27)$ was 5.6 IU/lit (2.1-10.2) in comparison with patients who did not ovulate $(n=21)$ which was $10.1 \mathrm{IU} / \mathrm{lit}(6.3-19)$ and the difference was statistically significant, $\mathrm{t}$ value $=-3, \mathrm{p}$ value $=0.0015$ $(p<0.05)$. Similarly, patients who ovulated were divided into patients who conceived (Group C) and who did not (Group D). The mean basal serum LH concentration in 
patients who conceived $(\mathrm{n}=15)$ was significantly low [3.9 IU/lit (2.1-5.6)] in comparison with patients who did not conceive $(\mathrm{n}=12)$ which was 5.9 IU/lit $(2.6-10.2)$ [ $\mathrm{t}$ value= $-1.74, p$ value $=0.04(\mathrm{p}<0.05)]$. Among the 15 patients who conceived, 3 patients had early pregnancy loss $(20 \%)$.

\section{DISCUSSION}

In 1935, Stein IF et al first described a symptom complex associated with anovulation. ${ }^{7}$ They described 7 patients with amenorrhea, hirsuitism and enlarged polycystic ovaries. They reported that all seven resumed menses and that two became pregnant after bilateral wedge resection of ovaries. They speculated that the thickened ovarian capsule prevented follicles from reaching and escaping from the surface of the ovary.

The diagnosis of polycystic ovarian syndrome is based on Rotterdam's criteria 2003. ${ }^{8}$ Two of the three following criteria are required for diagnosis.

- Menstrual abnormalities like amenorrhea, oligomenorrhea.

- Hyperandrogenism- clinically by acne, hirsuitism or laboratory elevated testosterone levels.

- Polycystic appearance of ovaries on ultrasound, containing multiple small follicles measuring 2-9 mm size.

The pathophysiology responsible for development of polycystic ovaries has puzzled gynaecologists and endocrinologists for many years and proven very difficult to define.

Compared to normally cycling women, those with PCOS generally exhibit increased serum LH concentrations, low-normal FSH levels and increased LH: FSH ratios. The increase in serum LH levels results from abnormal LH secretory dynamics, characterized by an increase in LH pulse frequency and to a lesser extent in pulse amplitude. ${ }^{9}$

The primary evidence indicating that excessive $\mathrm{LH}$ stimulation plays an important role in the pathophysiology of PCOS comes from examining the effects of treatment with GnRH antagonists and longacting GnRH agonists. These observations suggest that excessive LH secretion or stimulation may be an important cause of disordered follicular development and anovulation. $^{10}$

The present study was conducted to evaluate the deleterious effect of high concentration of serum LH on follicular development, ovulation, and conception and on developing fetus. The average BMI of the study patients was 26.4 who fall in the category of overweight which is comparable to the study by Adams et al. ${ }^{11}$
Adams et al studied on mean LH concentrations of 54 women treated for 182 cycles and found that there was no significant difference between the basal LH concentrations of women who did and did not ovulate (14versus21, $\mathrm{p}=0.2$ ). Basal luteinising hormone concentrations were significantly lower in those who conceived (12.4 IU/L) (Range 1.3-29 IU/L) than in those who did not $19 \mathrm{IU} / \mathrm{L}$ (3.5-50 IU/L) and in those whose pregnancy progressed $9.6 \mathrm{IU} / \mathrm{L}(1.3-29)$ than in those with early loss of pregnancy 17.9 IU/L (7.0-29.0). ${ }^{11}$

Shoham also states that LH exhibits an important role in the development of the growing follicle and maturation of the oocyte. It also seems that hyper secretion of LH during the follicular phase implies adverse effects on the fertility process. ${ }^{12}$ Homberg observed that impaired rates of fertilization, conception and miscarriage are obtained when LH levels are high before oocytes are collected, during ovulation induction or in women with regular cycles. He also concluded that Tonic hyper secretion of LH appears to induce premature oocyte maturation, causing the problems with fertilization and miscarriage. ${ }^{13}$

Regan investigated the relation between prepregnancy follicular-phase serum luteinising hormone (LH) concentrations and outcome of pregnancy was investigated prospectively in 193 women with regular spontaneous menstrual cycles. Of the 147 women with LH concentrations of less than 10 IU/l (normal LH group) $130(88 \%)$ conceived, whereas only $31(67 \%)$ of the 46 women with LH values of 10 IU/l or more (high LH group) did so. In the high LH group, $20(65 \%)$ of the pregnancies ended in miscarriage, whereas only $15(12 \%)$ of pregnancies in the normal LH group did so. ${ }^{14}$

Tariatzis concludes that in PCOS patients stimulated for IVF with HMG, follicular phase LH levels have an adverse effect on follicle and oocyte quality. Inappropriately raised $\mathrm{LH}$ appears to have a delirious effect on the pregnancy outcome. ${ }^{15}$

Kolibianakis et al found that a significant decrease of both ongoing pregnancy rate and implantation rate was present across groups of patients with increasing LH levels. The highest implantation rate and ongoing pregnancy rate was present in those patients with $\mathrm{LH}$ levels on day 8 of stimulation $\leq 0.5 \mathrm{IU} / 1 .{ }^{16} \mathrm{In}$ another study by Howles $\mathrm{C} \mathrm{M}$ et al, in women undergoing IVF treatment with a combination of CC and hMG, there were no pregnancies recorded if the urinary output of LH was elevated when measured two days prior to the day of hCG administration. ${ }^{5}$ Moreover, Stanger and Yovitch, have reported that high concentrations of luteinising hormone in the few days before oocytes were collected from women for in vitro fertilisation were associated with impaired rates of fertilisation and conception. ${ }^{4}$

Polycystic ovary syndrome is associated with hyper secretion of luteinizing hormone (LH) which has been implicated in the aetiology of early pregnancy loss. 
Inappropriately raised LH levels may have adverse effects on the developing oocyte or endometrium either directly, or indirectly by causing an elevation in testosterone and oestrogen levels. In a case-control study done by Watson et al, 21 women with early pregnancy loss and 10 multiparous controls were investigated and found that $81 \%$ of cases and one of ten control subjects had polycystic ovaries. Seventeen women with pregnancy loss had either raised urinary LH excretion or a premature LH surge, one control subject had a premature LH surge. These data demonstrate abnormalities in LH secretion in $81 \%$ of women with recurrent fetal loss. ${ }^{17}$

In a study by Yi Ping Zhong et al in 2011, comparison of endocrine profile and IVF outcome in anovulatory PCOS patients, ovulatory PCO and normal ovaries was done. They found that PCOS patients with central obesity, high LH and insulin resistance exhibited highest abortion rate. $^{18}$

Humaidan et al studied the effect of LH levels on D8 of stimulation in terms of ovarian response and pregnancy outcome. They conclude that circulating levels of LH on D8 have a significant effect on ovarian response and subsequent pregnancy outcome in IVF. LH should be neither too low and nor too high for the successful ovarian response for the implantation. ${ }^{19}$

\section{CONCLUSION}

To conclude, Tonic hyper secretion of LH in infertile patients with polcystic ovarian syndrome results in disturbed follicular growth, poor quality of oocytes causing problems with ovulation and conception. However, further studies involving a larger sample is needed to prove the deleterious effect of hypertonic luteinizing hormone in PCOS.

\section{ACKNOWLEDGMENTS}

Authors would like to thank the Management, Dean and the Research committee of Aarupadai Veedu Medical College for their continuous support and motivation.

Funding: No funding sources

Conflict of interest: None declared

Ethical approval: Not required

\section{REFERENCES}

1. Teede H, Deeks A, Moran L. Polycystic ovary syndrome: a complex condition with psychological, reproductive and metabolic manifestations that impacts on health across the lifespan. BMC Med. 2010;8:41.

2. Tartatzis BC, Grimbizis G. assisted reproduction techniques in polycystic ovarian syndrome. Ann NY Acad Sci. 1993;687:280-7.

3. Turhan NO, Artini PG, D Ambrogio G, Grogheni P, Battagha C, Gennazani AD. A comparative study of three ovulation induction protocols in polycystic ovarian disease patients in an in-vitro fertilization embryo transfer program. J Assist Report Genet. 1993;10:15-20.

4. Stranger JD, Yovich JL. Reduced in-vitro fertilization of human oocytes from patients with raised basal luteinizing hormone levels during the follicular phase. $\mathrm{Br} \mathrm{J}$ Obstet Gynecol. 1985 Apr;92(4):385-93.

5. Howles CM, Macnamee MC, Edwards RG, Goswamy R, Steptoe PC. Effect of high tonic concentrations of luteinising hormone on outcome on in-vitro fertilization. Lancet. 1986;30:521-2.

6. Balen AH, Tan SL, Jacob HS. Hyper secretion of luteinizing hormone. A significant cause of infertility and miscarriage. Br J Obstet Gynecol. 1993 Dec 1;100(12):1082-9.

7. Stein IF, Leventhal ML. Amenorrhea associated with bilateral polycystic ovaries. Am J Obstet Gynecol. 1935;29:181-191

8. Fr DD, Tarlatzis R. Revised 2003 consensus on diagnostic criteria and long-term health risks related to polycystic ovary syndrome. Fertil Steril. 2004;81:19-25.

9. Judd HL. Endocrinology of polycystic ovarian disease. Clin Obstet Gynecol. 1978;21:99-114.

10. Fawn BC. Observation in favour of normal early follicle development and disturbed dominant follicle selection in polycystic ovary syndrome. Gynecol Endocrinol. 1994 Jan;8(2):75-82.

11. Homburg R, Armar NA, Eshel A, Adams J, Jacobs HS. Influence of serum luteinising hormone concentrations on ovulation, conception, and early pregnancy loss in polycystic ovary syndrome. BMJ. 1988 Oct;297(6655):1024-6.

12. Shoham Z, Jacobs HS, Insler V. Luteinizing hormone: its role, mechanism of action, and detrimental effects when hyper secreted during the follicular phase. Fertil Steril. 1993;59:1153-6.

13. Baillieres HR. Adverse effects of luteinizing hormone on fertility: fact or fantasy. Clin Obstet Gynaecol. 1998 Dec;12(4):555-63.

14. Regan L, Owen EJ, Jacobs HS. Hyper secretion of luteinising hormone, infertility, and miscarriage. Lancet. 1990;336:1141-4.

15. Tarlatzis BC, Grimbizis G. The significance of high follicular phase luteinizing hormone levels in the treatment of women with polycystic ovarian syndrome by invitro fertilization. J Assist Reprod Genet. 1997 Jan 1;14(1):1-4.

16. Kolibianakis EM, Zikopoulos K, Schiettecatte J, Smitz J, Tournaye H, Camus M, et al. Profound LH suppression after $\mathrm{GnRH}$ antagonist administration is associated with a significantly higher ongoing pregnancy rate in IVF. Human Reprod. 2004 Nov 1;19(11):2490-6.

17. Watson H, Kiddy DS, Hamilton-Fairley D, Scanlon MJ, Barnard C, Collins WP et al. Hyper secretion of luteinizing hormone and ovarian steroids in women 
with recurrent early miscarriage. Hum Reprod. 1993;8:829-33.

18. Zhong YP, Ying Y, Wu HT, Zhou CQ, Xu YW, Wang $\mathrm{Q}$, et al. Comparison of endocrine profile and in vitro fertilization outcome in patients with PCOS, ovulatory PCO, or normal ovaries. Int J Endocrinol. 2012 Feb 28;2012.

19. Humaidan P, Bungum L, Bungum M, Andersen CY. Ovarian response and pregnancy outcome related to mid-follicular LH levels in women undergoing assisted reproduction with GnRH agonist down- regulation and recombinant FSH stimulation. Human Reprod. 2002 Aug 1;17(8):2016-21.

Cite this article as: Shanmugham D, Vidhyalakshmi RK, Shivamurthy HM. The effect of baseline serum luteinizing hormone levels on follicular development, ovulation, conception and pregnancy outcome in infertile patients with polycystic ovarian syndrome. Int J Reprod Contracept Obstet Gynecol 2018;7:31822. 